\title{
BMJ Open Prevalence and determinants of excessive daytime sleepiness in hypertensive patients: a cross-sectional study in Douala, Cameroon
}

Bertrand Hugo Mbatchou Ngahane, ${ }^{1,2}$ Motto Malea Nganda, ${ }^{1}$ Anastase Dzudie, ${ }^{1,3}$ Henry Luma, ${ }^{1}$ Félicité Kamdem, ${ }^{1}$ Henri Roger Ngote, ${ }^{1}$ Yves Monkam, ${ }^{1}$ Christopher Kuaban ${ }^{4}$

To cite: Mbatchou Ngahane BH, Nganda MM, Dzudie A, et al. Prevalence and determinants of excessive daytime sleepiness in hypertensive patients: a cross-sectional study in Douala, Cameroon. BMJ Open 2015;5:e008339. doi:10.1136/bmjopen-2015008339

- Prepublication history for this paper is available online. To view these files please visit the journal online (http://dx.doi.org/10.1136/ bmjopen-2015-008339).

Received 4 April 2015 Revised 26 June 2015 Accepted 8 July 2015



For numbered affiliations see end of article.

Correspondence to Dr Bertrand Hugo Mbatchou Ngahane; mbatchou. ngahane@yahoo.com

\section{ABSTRACT}

Objective: To determine the prevalence and determinants of excessive daytime sleepiness (EDS) among a group of sub-Saharan Africans living with hypertension.

Design: A cross-sectional study.

Setting: Cardiology outpatient unit of the Douala General Hospital in Cameroon.

Participants: Patients aged 15 years and over, being followed for hypertension between 1st January and 31st July 2013. Patients with unstable heart failure, stroke and head trauma were excluded.

Main outcome measure: EDS was the outcome of interest. It was defined as an Epworth sleeping scale greater or equal to 10 . Logistic regression was used to identify factors associated with EDS.

Results: A total of 411 patients participated in this study, with a sex ratio (male/female) of 0.58 and a mean age of 55.56 years. No patient was underweight and the mean body mass index was $30 \mathrm{~kg} / \mathrm{m}^{2}$. Controlled blood pressure was found in $92(22.4 \%)$ patients. The prevalence of EDS was $62.78 \%(95 \% \mathrm{Cl}$ 58.08 to 67.47$)$. The factors independently associated with EDS were: type 2 diabetes (OR 2.51;95\% $\mathrm{Cl} 1$ to 6.29 ), obesity (OR $2.75 ; 95 \% \mathrm{Cl} 1.52$ to 4.97 ), snoring (OR 7.92; $95 \% \mathrm{Cl} 4.43$ to 14.15 ) and uncontrolled blood pressure (OR 4.34; $95 \% \mathrm{Cl} 2.24$ to 8.40 ).

Conclusions: A significant proportion of hypertensive patients suffer from EDS and present a high risk of sleep apnoea. Preventive measures targeted on weight loss, type 2 diabetes and snoring should be considered among these patients.

\section{INTRODUCTION}

Excessive daytime sleepiness (EDS) is the most common concern for many people suffering from sleep disorder and has progressively moved from an unknown medical condition to a known public health risk. ${ }^{1}$ It has been defined by the American Academy of Sleep Medicine $^{2}$ as the inability to

\section{Strengths and limitations of this study}

- All participants were interviewed by a trained investigator, ensuring the accuracy of data collected.

- The reduced number of men in this study might have underappreciated the effect of gender on excessive daytime sleepiness.

- Ambulatory monitoring of blood pressure over $24 \mathrm{~h}$, which is the best method for the evaluation of controlled blood pressure, was not used.

maintain wakefulness and alertness during the major waking episodes of the day, with sleep occurring unintentionally or at inappropriate times almost daily. Reports of prevalence of EDS in various studies ranges from around $3 \%$ in randomly selected drivers to $20 \%$ in an elderly cohort, ${ }^{3}$ and as high as $22.6 \%$ in a study of EDS and risk of occupational injuries in non-shift daytime workers. ${ }^{4}$

Hypertension is a pathology associated with high morbidity and mortality rates in the developed and developing world. It is estimated to cause 7.5 million deaths, about $12.8 \%$ of the total number of deaths worldwide. ${ }^{5}$ Across the WHO regions, the prevalence of raised blood pressure (BP) in adults was highest in Africa, where it was $46 \%$ for both sexes. ${ }^{5}$ In Sub-Saharan Africa, it is the most frequent cardiovascular risk factor for cardiovascular disease, with a prevalence estimate of $47.5 \%$ in a self-selected sub-Saharan urban population in Cameroon. ${ }^{6} 7$

An association between EDS and hypertension has been a frequent finding in recent studies. In a 5-year follow-up study of 157 adults by Goldstein $e t a l,{ }^{8}$ patients with more symptoms of EDS had increased casual and sleep BP variability during waking hours. 
These individuals with increased symptoms of EDS were more likely to be diagnosed with hypertension within the 5-year follow-up period. Likewise, Newman et at reported increased cardiovascular disease (CVD) mortality of $200 \%$ for men and $40 \%$ for women in patients with EDS. These were also associated with an increase in cardiovascular events.

With the evidence of EDS and its relationship with hypertension and CVD, it remains underdiagnosed and undermanaged, especially in sub-Saharan Africa. Adewole $e t a l^{10}$ reported the prevalence of risk of sleep apnoea to be $19 \%$ in Nigeria while Mapoure et $a l^{11}$ reported 3.8\% prevalence of EDS in Cameroon. These studies were, however, carried out in the general population, and studies in the cardiovascular and particularly the hypertensive population remain scarce. We therefore aimed in this study to determine the prevalence and determinants of EDS among hypertensive patients.

\section{METHODS}

\section{Study design and setting}

This was a cross-sectional study conducted at the cardiology outpatient unit of the Douala General Hospital (DGH) from 1st January to 31st July 2013. Douala is a seaside city and the economic capital of Cameroon, hosting many industries. Its population in 2010 was estimated at 2.1 million inhabitants, originating from different regions of the country.

\section{Participants}

Patients who presented themselves at the cardiology outpatient unit of the DGH for a routine consultation were included in the study. They were all above 15 years of age, had been diagnosed as hypertensive and were followed-up at the cardiology outpatient unit. Patients were excluded from the study if they were on sedatives, or if they had a past or present history of stroke, heart failure or head trauma.

\section{Data collection}

Patients were consecutively invited to participate in the study. Data were obtained from the patients on a questionnaire during an interview administered by a trained investigator. Demographic characteristics, medical history and information on smoking status and alcohol consumption, were collected. Biological parameters (blood uric acid, lipid profile) were extracted from the patients' files. The Epworth sleep questionnaire was administered and the anthropometric data (weight, height, neck circumference, waist circumference) as well as the $\mathrm{BP}$, were measured.

\section{Definitions}

The weight (in $\mathrm{kg}$ ) of the patient was collected with the help of a scale balance (patient standing at the anatomical position on a scale balance) and the height (in $\mathrm{cm}$ ) with the help of a stadiometer (patient standing at the anatomical position in front of the stadiometer). These enabled us to calculate the body mass index (BMI) with the formula weight/(height $\times$ height) that classified patients to either being obese (BMI $\geq 30 \mathrm{~kg} / \mathrm{m}^{2}$ ) or not. ${ }^{12}$ Neck circumference was measured using a metre tape at the mid-way point of the neck between mid-cervical spine and mid-anterior neck to $0.5 \mathrm{~cm}$, if palpable, just below the laryngeal prominence. ${ }^{13}$ The waist circumference was measured at the narrowest waist level, or if this was not apparent, at the midpoint between the lowest rib and the top of the hip bone (iliac crest). The tape was placed horizontal to the body, not too tight or too loose. ${ }^{14}$

BP was measured twice on the upper left arm, after at least 5 min of rest, using a validated automatic BP device (Spengler) and the second BP value was used for analysis. ${ }^{6}$ Hypertension was diagnosed if the patient had a systolic (and/or diastolic) BP of 140 (90) $\mathrm{mm} \mathrm{Hg}$ or higher on two different occasions, or if the patient was on BP lowering medications over the last 15 consecutive days. Controlled BP was defined as systolic BP less than $140 \mathrm{~mm} \mathrm{Hg}$ and diastolic BP less than $90 \mathrm{~mm} \mathrm{Hg}$ in patients under BP lowering medications. ${ }^{6}$ Participants were considered to have diabetes if they were treated with hypoglycaemic medications (insulin diabetes medications) or if their fasting blood glucose levels reached $126 \mathrm{mg} / \mathrm{dL}$ or more. ${ }^{15}$ Dyslipidaemia was defined by high total cholesterol $(>2.7 \mathrm{~g} / \mathrm{L})$, high levels of triglycerides $(>1.4 \mathrm{~g} / \mathrm{L})$, high levels of low-density lipoprotein $(>1.6 \mathrm{~g} / \mathrm{L})$ or low levels of high-density lipoprotein cholesterol $(<0.29 \mathrm{~g} / \mathrm{L}) .{ }^{16}$ Waist circumference $>94 \mathrm{~cm}$ in men or $80 \mathrm{~cm}$ in women was considered to be high. Neck circumference was considered high when it was $\geq 43 \mathrm{~cm} .{ }^{13}$ Participants who smoked at least one cigarette per day were classified as current smokers and those who had stopped smoking for more than 3 years were classified as former smokers. Patients were considered snorers when their bed partners or house mates testified to it. Hyperuricaemia was defined by blood uric acid level greater than $70 \mathrm{mg} / \mathrm{L}^{16}$

EDS was the outcome variable. It was defined as an Epworth Sleepiness Scale (ESS) score $\geq 10$. The ESS is a scale used to measure sleep propensities in eight different situations of real-life: (1) sitting and reading, (2) watching television, (3) sitting, inactive in a public place, (4) as a passenger in a car for an hour without a break, (5) lying down to rest in the afternoon when circumstances permit, (6) sitting and talking to someone, (7) sitting quietly after a lunch without alcohol and (8) in a car while stopped for a few minutes in traffic. The range of an item-score was $0-3$ on the Likert scale: never doze $($ score $=0)$, slight chance of dozing (score $=1$ ), moderate chance of dozing (score $=2$ ) and high chance of dozing (score $=3$ ). The ESS score is the sum of the eight item scores (range, 0-24); the higher scores indicate being more sleepy. ${ }^{3}$

\section{Statistical analysis}

Data were analysed using the software IBM SPSS Statistics, V.20.0. (Armonk, NY: IBM Corp). Descriptive 
statistics included proportions for categorical variables and means for continuous variables. Factors associated with EDS were identified using the $\chi^{2}$ test in the univariate analysis. Significant variables from the $\chi^{2}$ test were then included in the multivariate logistic regression model for the assessment of the independent effect of individual factors. The ORs and their 95\% CIs were reported. A p value of 0.05 was considered statistically significant.

\section{Ethical issue}

The study was approved by the National Ethics Committee and oral consent was obtained from each participant before the recruitment.

\section{RESULTS}

\section{Participants}

Out of 508 patients invited to participate in the study, $470(92.5 \%)$ accepted. As shown in figure 1, 32 patients were excluded due to the presence of one or more exclusion criteria and 27 questionnaires were further excluded from analysis due to incomplete information; a total of 411 patients were finally included in the study (figure 1).

\section{Baseline characteristics of participants}

From 411 participants, females made up the majority with a total of $260(63.3 \%)$. The age of the respondents ranged from 27 to 90 with a mean age of $55.5 \pm 9.7$ years. The mean BMI was $30 \pm 81 \mathrm{~kg} / \mathrm{m}^{2}$ (range 21-48.3). On the contrary, $226(54.9 \%)$ patients were obese and 15 $(3.6 \%)$ had morbid obesity. The percentage of controlled BP was $22.4 \%$ (92 patients). Two hundred and fifty-eight (258) patients had an Epworth Sleeping Score $\geq 10$, giving a prevalence of EDS at $62.8 \%$ (95\% CI 58 to 67.4). The other characteristics of participants are given in table 1.

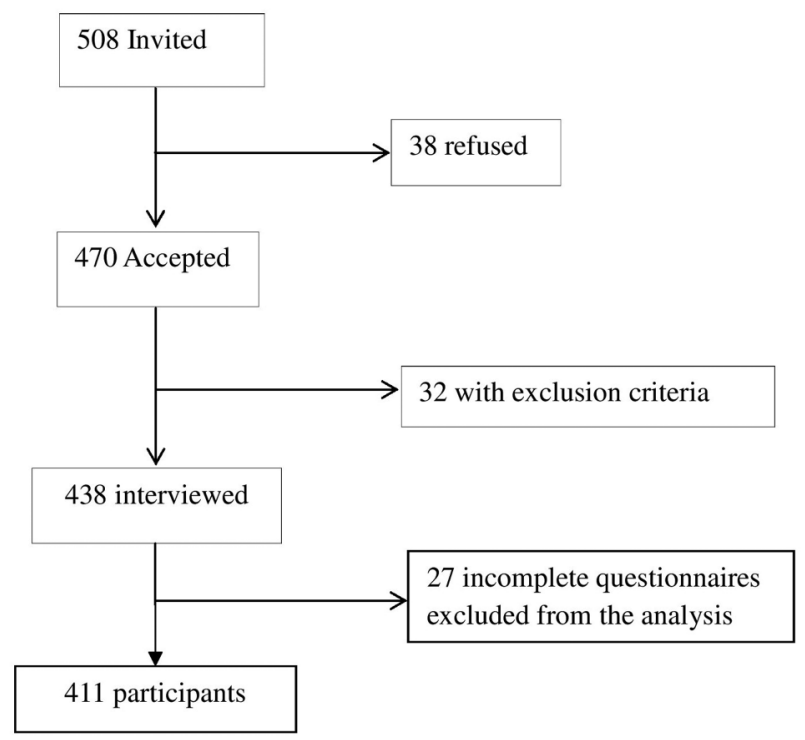

Figure 1 Flow chart of participants.

\section{Factors associated with EDS}

From the univariate analysis (table 2), the following variables were associated with EDS: uncontrolled BP, obesity, high abdominal circumference, hyperuricaemia, type 2 diabetes and secondary school level of education. Level of education, age and gender were not associated with EDS. After the multivariate analysis (table 2), the factors independently associated with EDS were: type 2 diabetes (OR 2.51; 95\% CI 1 to 6.29), obesity (OR 2.75; 95\% CI 1.52 to 4.97 ), snoring (OR 7.92; 95\% CI 4.43 to 14.15 ) and uncontrolled BP (OR 4.34; $95 \%$ CI 2.24 to 8.40$)$.

\begin{tabular}{|c|c|}
\hline Characteristics & Frequency n (\%) \\
\hline \multicolumn{2}{|l|}{ Gender } \\
\hline Male & $151(36.7)$ \\
\hline Female & $260(63.3)$ \\
\hline \multicolumn{2}{|l|}{ Age (years) } \\
\hline$<40$ & $18(4.4)$ \\
\hline $40-49$ & $92(22.4)$ \\
\hline $50-59$ & $165(40.1)$ \\
\hline $60-69$ & $103(25.1)$ \\
\hline $70-79$ & $28(6.8)$ \\
\hline 80-89 & $05(1.2)$ \\
\hline \multicolumn{2}{|l|}{ Type 2 diabetes } \\
\hline Yes & $53(12.9)$ \\
\hline No & $358(87.1)$ \\
\hline \multicolumn{2}{|c|}{ Neck circumference } \\
\hline Normal & $383(93.2)$ \\
\hline High & $28(6.8)$ \\
\hline \multicolumn{2}{|c|}{ Waist circumference } \\
\hline Normal & 104 (25.3) \\
\hline High & $307(74.7)$ \\
\hline \multicolumn{2}{|l|}{ Smoking } \\
\hline Yes & $9(2.2)$ \\
\hline No & 364 (88.6) \\
\hline Ex-smoker & $38(9.2)$ \\
\hline \multicolumn{2}{|c|}{ Alcohol consumption } \\
\hline Yes & $124(30.2)$ \\
\hline No & $287(69.8)$ \\
\hline \multicolumn{2}{|l|}{ Dyslipidaemia } \\
\hline Yes & $56(13.6)$ \\
\hline No & $355(86.4)$ \\
\hline \multicolumn{2}{|l|}{ Hyperuricaemia } \\
\hline Yes & $117(35.5)$ \\
\hline No & $212(64.5)$ \\
\hline \multicolumn{2}{|l|}{ BMI $\left(\mathrm{kg} / \mathrm{m}^{2}\right)$} \\
\hline $18.5-24.99$ & $43(10.5)$ \\
\hline 25-29.99 & $142(34.5)$ \\
\hline$\geq 30$ & $226(55)$ \\
\hline \multicolumn{2}{|l|}{ ESS } \\
\hline$\geq 10$ & 258 (62.78) \\
\hline$<10$ & $153(37.22)$ \\
\hline \multicolumn{2}{|c|}{ Controlled blood pressure } \\
\hline Yes & $92(22.4)$ \\
\hline No & $319(77.6)$ \\
\hline
\end{tabular}


Table 2 Univariate and multivariate analysis of factors associated with EDS

\begin{tabular}{|c|c|c|c|c|}
\hline Variables & EDS (\%) & p Value & aOR $(95 \% \mathrm{Cl})$ & Adjusted $p$ value \\
\hline \multicolumn{5}{|c|}{ Level of education } \\
\hline$<$ Secondary & $63(54.8)$ & 0.03 & 1.45 (0.78 to 2.68$)$ & 0.231 \\
\hline$\geq$ Secondary & $195(65.9)$ & & & \\
\hline \multicolumn{5}{|l|}{ Uric acid } \\
\hline High & $81(69.2)$ & 0.04 & 0.41 (0.78 to 2.54$)$ & 0.252 \\
\hline Low & $123(58)$ & & & \\
\hline \multicolumn{5}{|c|}{ Abdominal circumference } \\
\hline High & $210(68.4)$ & 0.000 & $1.73(0.91$ to 3.28$)$ & 0.090 \\
\hline Low & $48(46.2)$ & & & \\
\hline \multicolumn{5}{|l|}{ Type 2 diabetes } \\
\hline Yes & $42(79.2)$ & 0.08 & 2.51 (1.00 to 6.29$)$ & 0.048 \\
\hline No & $216(60.3)$ & & & \\
\hline \multicolumn{5}{|l|}{ Obesity } \\
\hline Yes & $169(74.8)$ & 0.000 & 2.75 (1.52 to 4.95$)$ & 0.001 \\
\hline No & $89(48.1)$ & & & \\
\hline \multicolumn{5}{|l|}{ Snoring } \\
\hline Yes & $174(81.3)$ & 0.000 & 7.92 (4.43 to 14.15$)$ & 0.000 \\
\hline No & $84(42.6)$ & & & \\
\hline \multicolumn{5}{|l|}{ Blood pressure } \\
\hline Uncontrolled & $226(70.8)$ & 0.000 & 4.34 (2.24 to 8.40$)$ & 0.000 \\
\hline Controlled & $32(34.8)$ & & & \\
\hline
\end{tabular}

\section{DISCUSSION}

In this study, we found that more than 6 of 10 hypertensive patients have EDS. This condition was significantly associated with type 2 diabetes, obesity, snoring and uncontrolled BP.

EDS was screened in $62.8 \%$ of participants. This was similar to the $67.8 \%$ prevalence of EDS in hypertensive and obstructive sleep apnoea patients reported by Wang et $a l^{17}$ in China. It was greater than the $3.8 \%$ reported by Mapoure $e a^{11}$ in the general population in Cameroon. In a study among middle-aged adults in France, the prevalence of EDS was estimated at $18 \% .^{18}$ These findings show that EDS in hypertensive patients is high and the marked difference between EDS prevalence in the general population versus hypertensive patients supports the fact that hypertension is a well documented risk factor for developing sleep-related disorders. ${ }^{19}$

The factors independently associated with EDS in this study were type 2 diabetes, obesity, snoring and uncontrolled BP. Akintunde et $a l^{19}$ found an association between snoring and EDS among hypertensive patients. In addition, sleep disorders have been shown to be independently associated with obesity and hypertension. ${ }^{20}{ }^{21}$ In the Wisconsin sleep cohort study, a one SD difference in BMI was associated with a fourfold increase in the prevalence of sleep-disordered breathing. ${ }^{22}$ Snoring has been reported as one of the cardinal manifestations of sleep related disorders and is sometimes taken for sleep-disordered breathing itself. ${ }^{18}$ Our study shows an independent relationship between EDS and type 2 diabetes. Sleep apnoea, which is a major cause of EDS, has been shown to be associated with insulin resistance and type 2 diabetes. ${ }^{23} \mathrm{BP}$ control was associated with EDS in this study. Several other studies have reported sleep apnoea syndrome and EDS as being related to resistant hypertension. ${ }^{24}$ Impaired sodium handling, sympathetic activation, accelerated arterial stiffening and impaired cardiorenal haemodynamics contribute to drug resistant hypertension development in EDS, and sleep apnoea. ${ }^{24}$

Hyperuricaemia was not associated with EDS in our study. However, Verhulst $e t a l^{25}$ reported sleep disordered breathing to be related to increased levels of serum uric acid, independent of abdominal adiposity; a finding that contributed to the mechanisms linking sleep disordered breathing with cardiovascular morbidity.

One strength of this study was the fact that all participants were interviewed by an investigator who ensured that data were accurately collected. We also used multivariate logistic regression analysis to investigate factors associated with EDS. This enabled us to avoid the effects of confounders and to obtain factors independently associated with EDS. However, this study has some limitations: the absence of sleep diagnostic tools in our context prevented us from investigating sleep apnoea itself. Nevertheless, EDS has been reported to be positively associated with obstructive sleep apnoea, ${ }^{26}$ thus serving as a surrogate in this study. The male sex might have been underappreciated in the study as 31 of the 38 subjects who did not give their consent were males. Likewise, ambulatory monitoring of BP over $24 \mathrm{~h}$, which is the best method for the evaluation of controlled BP, was not used. Another limitation of this study is that our results cannot be generalised to all hypertensive 
patients. Further studies including patients from other healthcare facilities in Cameroon are needed.

\section{CONCLUSION}

This study has demonstrated that a high proportion of hypertensive patients suffer from EDS. This was significant in patients with diabetes mellitus: in snorers, in obese patients and in patients with uncontrolled BP. Patients who feel very dizzy during the day should consult their physician for screening while health personnel involved in the management of hypertensive patients should screen EDS and consider weight loss in positive patients. Health-related organisations and policymakers should promote programmes of sensitisation on EDS as well as encourage the purchase of sleep diagnostic tools in our context. Researchers should use this study as baseline for further studies on sleep related disorders in hypertensive patients in sub-Saharan Africa.

\section{Author affiliations}

${ }^{1}$ Department of Internal Medicine, Douala General Hospital, Douala, Cameroon ${ }^{2}$ Faculty of Medicine and Pharmaceutical Sciences, University of Douala, Douala, Cameroon

${ }^{3}$ Faculty of Medicine, University of Cape Town, Cape Town, South Africa

${ }^{4}$ Faculty of Health Sciences, University of Bamenda, Bamenda, Cameroon

Acknowledgements The authors thank all the hypertensive patients who agreed to participate in this study. The authors also thank the Pan African Thoracic Society MECOR course staff for their contribution during the preparation of this manuscript.

Contributors BHMN conceptualised the study, designed the protocol and analysed the data. MMN collected the data and drafted the manuscript. AD designed the protocol and revised the manuscript. CK revised the manuscript. FK, HHR and YM participated in data collection. HL revised the manuscript and contributed to administrative and technical support.

Competing interests None declared.

Ethics approval Cameroon National Ethics Committee.

Provenance and peer review Not commissioned; externally peer reviewed.

Data sharing statement No additional data are available.

Open Access This is an Open Access article distributed in accordance with the Creative Commons Attribution Non Commercial (CC BY-NC 4.0) license, which permits others to distribute, remix, adapt, build upon this work noncommercially, and license their derivative works on different terms, provided the original work is properly cited and the use is non-commercial. See: http:// creativecommons.org/licenses/by-nc/4.0/

\section{REFERENCES}

1. Rosenthal L. Excessive daytime sleepiness: from an unknown medical condition to a known public health risk. Sleep Med 2005;6:485-6.

2. American Academy of Sleep Medicine. The international classification of sleep disorders, revised: diagnostic and coding manual. Chicago, IL: American Academy of Sleep Medicine, 2001.

3. Ruggles K, Hausman N. Evaluation of excessive daytime sleepiness. WMJ 2003;102:21-4.
4. Melamed S, Oksenberg A. Excessive daytime sleepiness and risk of occupational injuries in non-shift daytime workers. Sleep 2002;25:315-22.

5. Global health observatory data. Raised blood pressure, 2015 [Intenet]. http://www.who.int/gho/ncd/risk_factors/blood_pressure_ prevalence_text/en/ (accessed 20 Mar 2015).

6. Hendriks ME, Wit FW, Roos MT, et al. Hypertension in sub-Saharan Africa: cross-sectional surveys in four rural and urban communities. PLOS ONE 2012;7:e32638.

7. Dzudie A, Kengne AP, Muna WF, et al. Prevalence, awareness, treatment and control of hypertension in a self-selected sub-Saharan African urban population: a cross-sectional study. BMJ Open 2012;2: pii: e001217.

8. Goldstein IB, Ancoli-Israel S, Shapiro D. Relationship between daytime sleepiness and blood pressure in healthy older adults. $A m J$ Hypertens 2004;17:787-92.

9. Newman AB, Spiekerman CF, Enright $P$, et al. Daytime sleepiness predicts mortality and cardiovascular disease in older adults. The Cardiovascular Health Study Research Group. J Am Geriatr Soc 2000;48:115-23.

10. Adewole OO, Hakeem A, Fola A, et al. Obstructive sleep apnea among adults in Nigeria. J Natl Med Assoc 2009;101:720-5.

11. Mapoure NY, Luma HM, Mbatchou Nngahane BH, et al. Prévalences des facteurs de risque d'accident vasculaire cérébral en milieu urbain à Douala, Cameroun. Revue de Médecine et de Pharmacie 2012;2:143-51.

12. [No authors listed]. Clinical Guidelines on the Identification, Evaluation, and Treatment of Overweight and Obesity in AdultsThe Evidence Report. National Institutes of Health. Obes Res 1998;6(Suppl 2):51S-209S.

13. Onat A, Hergenc G, Yuksel $H$, et al. Neck circumference as a measure of central obesity: associations with metabolic syndrome and obstructive sleep apnea syndrome beyond waist circumference. Clin Nutr 2009;28:46-51.

14. Welborn TA, Dhaliwal SS, Bennett SA. Waist-hip ratio is the dominant risk factor predicting cardiovascular death in Australia. Med J Aust 2003;179:580-5.

15. World Health Organization. Screening for Type 2 Diabetes Report of a World Health Organization and International Diabetes Federation meeting. Geneva, 2003.

16. Gupta R, Rastogi P, Sarna M, et al. Body-mass index, waist-size, waist-hip ratio and cardiovascular risk factors in urban subejcts. $J$ Assoc Physicians India 2007;55:621-7.

17. Wang $Q$, Zhang $C$, Jia $P$, et al. The association between the phenotype of excessive daytime sleepiness and blood pressure in patients with obstructive sleep apnea-hypopnea syndrome. Int $J$ Med Sci 2014;11:713-20.

18. Meslier N, Vol S, Balkau B, et al. Prévalence des symptomes du syndrome d'apnées du sommeil. Etude dans une population francaise d'âge moyen. Rev Mal Respir 2007;24(3 Pt 1):305-13.

19. Akintunde $A A$, Okunola OO, Oluyombo R, et al. Snoring and obstructive sleep apnoea syndrome among hypertensive Nigerians: prevalence and clinical correlates. Pan Afr Med J 2012;11:75

20. Young T, Peppard PE, Taheri S. Excess weight and sleepdisordered breathing. J Appl Physiol (1985) 2005;99:1592-9.

21. Carlson JT, Hedner JA, Ejnell H, et al. High prevalence of hypertension in sleep apnea patients independent of obesity. Am J Respir Crit Care Med 1994;150:72-7.

22. Roos M, Althaus W, Rhiel C, et al. [Comparative use of MESAM IV and polysomnography in sleep-related respiratory disorders]. Pneumologie 1993;47(Suppl 1):112-18.

23. Caples SM, Garcia-Touchard A, Somers VK. Sleep-disordered breathing and cardiovascular risk. Sleep 2007;30:291-303.

24. Thomopoulos C, Michalopoulou H, Kasiakogias A, et al. Resistant hypertension and obstructive sleep apnea: the sparring partners. Int J Hypertens 2011;2011:947246.

25. Verhulst SL, Van Hoeck K, Schrauwen N, et al. Sleep-disordered breathing and uric acid in overweight and obese children and adolescents. Chest 2007;132:76-80.

26. Mermigkis C, Bouloukaki I, Schiza SE. Insomnia and excessive daytime sleepiness in obstructive sleep apnea: only different clinical phenotypes? Sleep Breath 2015. doi:10.1007/s11325-015-1170-6 [published online first: 9 April 2015]. 